\title{
“O Dr. Alô falou para não contrariar": a consolidação da Psiquiatria no Paraná na primeira metade do século $X X$
}

\section{The consolidation of Psychiatry in Paraná, in the first half of the twentieth century}

\section{Andrea de Alvarenga Lima*}

Universidade Federal do Paraná - UFPR, Curitiba, Paraná, Brasil

\section{Adriano Furtado Holanda**}

Universidade Federal do Paraná - UFPR, Curitiba, Paraná, Brasil

\begin{abstract}
RESUMO
Através de uma retomada da história de vida e dos escritos do psiquiatra paranaense Alô Ticoulat Guimarães (1903-1985), o presente trabalho objetiva evidenciar as inter-relações entre o contexto social e a constituição do saber psiquiátrico em Curitiba, Paraná. Entre outros muitos e variados cargos, Dr. Alô foi o primeiro professor catedrático de clínica Psiquiátrica da Universidade do Paraná e, por mais de três décadas, esteve à frente dos dois maiores hospitais psiquiátricos do estado. Tendo o método fenomenológico como substrato, foram utilizados procedimentos da pesquisa historiográfica documental e consultados os acervos da UFPR, da Biblioteca Pública do Paraná e da Federação Espírita do Paraná. Apoiados nas reflexões do sociólogo Norbert Elias (1897-1990), sobre as relações entre indivíduo e sociedade, discute-se as diferentes facetas (econômica, cultural, social) inter-relacionadas no processo específico que, em Curitiba, constitui uma configuração social que centraliza tanto poder na mão de um único indivíduo, "o especialista".
\end{abstract}

Palavras chave: Saúde Mental, História da Psiquiatria, Paraná, Norbert Elias.

\footnotetext{
ABSTRACT

This article traces the writings and life story of the eminent psychiatrist from Paraná, Alo Ticoulat Guimaraes (1903-1985). It aims to show the interrelationships between the social context and the development of psychiatric knowledge in Curitiba. Among his many and varied positions, Dr. Alo was the first Professor of Clinical Psychiatry at the Federal University of Paraná (UFPR) and for more than three decades he was the head of two major psychiatric hospitals in the state. Having the phenomenological method as philosophical ground, we used the procedures of historical research and consulted the documentary collections from the UFPR, Paraná Public Library and the Spiritist Federation of Parana. Based on the teachings of the sociologist Norbert Elias (1897-1990) on the relationship between the individual and society, the paper discusses the various interrelated aspects in the process that gave rise to a specific social configuration in Curitiba, concentrating a great deal of power in the hands of one individual, the "expert".
} 
Keywords: Mental health, History of Psychiatry, Paraná, Norbert Elias.

A produção recente da história da Psiquiatria e do atendimento à doença mental, no Brasil, revela uma multiplicidade, tanto de objetos, abordagens e problemas, quanto de diferentes lugares a partir dos quais essa História é escrita. Ao mesmo tempo, apresenta áreas obscuras e ainda pouco estudadas (LIMA; HOLANDA, 2010). É a uma dessas zonas cronológicas e geográficas, pouco conhecidas e ainda não valorizadas pela historiografia que nos voltamos, no presente trabalho, para apresentar e discutir resultados selecionados da pesquisa de Mestrado em Psicologia, intitulada Psiquiatria e Espiritismo no atendimento à doença mental: a história do Hospital Espírita de Psiquiatria Bom Retiro (Curitiba 1930-1950).

Instituição filantrópica criada e mantida até os dias de hoje pela Federação Espírita do Paraná, o hospital Bom Retiro foi inaugurado em Curitiba, em 1945, com o propósito de prestar atendimento caritativo aos doentes mentais. Seu funcionamento atual é marcado por uma filosofia de trabalho que circunscreve um campo de relações onde co-existem práticas médicas e práticas religiosas, ou seja, onde há a possibilidade de, ao fenômeno da doença mental, ser dada assistência religiosa ou serem aplicadas terapêuticas religiosas de maneira complementar ao tratamento tradicional da Psiquiatria. A dissertação, como um todo, consistiu em um estudo que parte de um fato pontual, a inauguração do hospital, na busca das condições históricas que possibilitaram esse evento, para compreender como a doença mental foi encarada nesse contexto.

No recorte aqui exposto, toma-se por objeto a figura do psiquiatra paranaense Alô Ticoulat Guimarães (1903-1985), Diretor Clínico desse hospital por mais de trinta anos, para, através de uma retomada de sua história de vida e de seus escritos, compreender as inter-relações entre o contexto social e a constituição do saber psiquiátrico em Curitiba e perceber de que forma as redes de alianças se distribuíram nesse sistema.

Tendo o método fenomenológico como pressuposto filosófico e norteador de um pensamento metódico na coleta e análise de dados, foram utilizados procedimentos da pesquisa historiográfica e consultados: o acervo da Memória da Universidade Federal do Paraná; a coleção especial da Biblioteca das Ciências da Saúde, da Universidade Federal do Paraná; a seção de documentação paranaense da Biblioteca Pública do Paraná, com especial relevo à coleção do periódico "Revista Médica do Paraná" (1932-1949); o acervo documental do Hospital Espírita do Paraná; os Livros de Atas e Atos da Diretoria da Federação Espírita do Paraná (FEP), e o acervo de periódicos da biblioteca da FEP. 
Qual o sentido de se pensar a História da Psiquiatria no Paraná a partir do Dr. Alô? Para Curitiba, Dr. Alô é um ícone e pode ser tomado como uma metáfora para a trajetória da Psiquiatria clássica na cidade. Na década de 1980, uma expressão de linguagem usada em Curitiba, quando alguém insistia em alguma bobagem, teimava em relação a um assunto qualquer ou contava uma história difícil de acreditar, era um brincalhão: "O Dr. Alô mandou não contrariar!". assertiva que, de imediato, descredenciava o indivíduo em questão, taxando-o de insano.

Em 1985, quando o Dr. Alô Guimarães faleceu, aos 81 anos de idade, foram decretados três dias de luto oficial, tanto na Universidade Federal do Paraná, onde era Professor Emérito Catedrático de Clínica Psiquiátrica, como no município de Curitiba, sua cidade natal, onde desempenhou vários cargos administrativos. Centenas de pessoas compareceram ao seu guardamento, na capela da Universidade Federal do Paraná, e acompanharam seu sepultamento, onde familiares, ex-alunos e colegas fizeram pronunciamentos elogiosos ao professor. Na ocasião, foram tecidas considerações respeitosas sobre os sucessos da longa carreira do Dr. Alô Guimarães que, para além da Psiquiatria, se expandiam para as áreas da Medicina Legal e da atuação política e social (ALVES; PILOTTO, 1994).

Ao longo de sua carreira, Alô Guimarães acumulou inúmeros cargos de relevância. Foi - além de primeiro Professor Catedrático de Clínica Psiquiátrica da Universidade do Paraná e Maçom - jornalista da Gazeta do Povo, Diretor do Gabinete Médico Legal, Diretor Clínico do Hospital Psiquiátrico Nossa Senhora da Luz e do Hospital Psiquiátrico Espírita do Bom Retiro, médico particular do Governador Manoel Ribas por vários anos, Presidente da Associação Médica do Paraná, Correspondente Nacional da Academia Nacional de Medicina, Presidente do Jóquei Clube do Paraná, Presidente do Rotary Clube, Vice-Presidente do Partido Social Democrata, Prefeito da cidade de Curitiba, duas vezes Secretário da Saúde, Deputado Estadual e Senador e Vice-Presidente da Comissão de Saúde do Senado Federal. Após seu falecimento, o nome Alô Guimarães voltou a circular na mídia nacional quando da publicação do livro do curitibano Austregésilo Carrano Bueno (2001), Canto dos Malditos, que veio, depois a inspirar o filme Bicho de Sete Cabeças (2000). No livro, Carrano conta sua experiência em hospitais psiquiátricos e denuncia a violência dos tratamentos a que foi submetido, sendo especialmente veemente em relação à figura do Dr. Alô. Sob alegação de calúnia e difamação à memória do psiquiatra, os familiares do Dr. Alô Guimarães moveram um processo que proibiu a circulação do livro.

A atenção dada neste trabalho ao personagem de Alô Guimarães e ao seu lugar na trajetória da Historia da Psiquiatria do Paraná não tem por objetivo denunciar, redimir ou enaltecer seu caráter. Apoiada nas reflexões do sociólogo Norbert Elias (1897-1990) sobre as relações 
entre indivíduo e sociedade, a presente análise não o toma como indivíduo isolado e desenraizado do solo social comum, mas como uma dentre as muitas "unidades semi-autônomas, dependentes umas das outras e ligadas umas às outras de formas muito diversas" em uma sociedade (ELIAS, 2008, p. 193). O que nos move não é a busca da identificação de um pensamento fundador da Psiquiatria no Paraná, mas a tentativa de compreender as diferentes facetas (econômica, cultural, social) inter-relacionadas no processo social específico que, em Curitiba, constitui uma formação social centralizadora de imenso poder na mão de um único indivíduo, aqui "o especialista".

Tomamos dois conceitos centrais do pensamento sistêmico eliasiano para a construção da presente discussão, que são o de "configuração social" e "habitus social".

A primeira contribuição à problemática da pesquisa vem da compreensão de sociedade que Norbert Elias constrói, a qual encontra expressão no conceito de "configuração social". Reiteradas vezes ao longo de sua obra, Elias condena a visão, predominante tanto na vida cotidiana quanto nas ciências humanas, segundo a qual a sociedade é constituída por estruturas exteriores aos indivíduos família, escola, comunidade - , e os indivíduos são, ao mesmo tempo, "envoltos pela sociedade e separados dela por uma membrana invisível e intransponível" (ELIAS, 2008, p. 15). Essa reificação de conceitos deturpa e dificulta o entendimento da vida dos seres humanos em comunidade. Para o autor, a sociedade não se opõe ao indivíduo: é necessário ultrapassar esse entendimento dos grupos sociais como estruturas estáticas, acima e além dos indivíduos.

Como veremos, essas concepções tradicionais serão substituídas por uma visão mais realista das pessoas que, através das suas disposições e inclinações básicas são orientadas umas para as outras e unidas umas às outras das mais diversas maneiras. Essas pessoas constituem teias de interdependência ou configurações de muitos tipos, tais como famílias, escolas, cidades, estratos sociais ou estados (ELIAS, 2008, p. 15)

No intuito de expressar essa compreensão sistêmica de sociedade, e "afrouxar o constrangimento social de falarmos e pensarmos como se o 'indivíduo' e a 'sociedade' fossem antagônicos e diferentes", Elias (2008, p. 141) irá forjar a expressão "configuração social".

Tal conceito instrumentaliza $\mathrm{o}$ entendimento da Psiquiatria paranaense da época como uma configuração social singular. Mais que um saber, uma forma de convívio: uma instância da vida em comum que estruturou padrões de relação entre os indivíduos da cidade, oferecendo-Ihes "uma gama mais ou menos restrita de funções e modos de comportamento possíveis" (ELIAS, 1994, p. 21). 
A partir dessa perspectiva, percebe-se o processo de consolidação da Psiquiatria como o estabelecimento de uma nova estrutura e regularidade nas relações de interdependência entre as pessoas, que veio a se somar aos padrões pré-existentes na sociedade curitibana, tensionando-os e remodelando-os. O campo da Psiquiatria instaura, no que diz respeito à doença mental, tanto no interior das instituições hospitalares quanto nas comunidades científica e política de Curitiba, uma nova distribuição de funções e, conseqüentemente, de poder, que reorganiza os indivíduos em séries de alianças e antagonismos.

Outro conceito central à obra de Elias, e estreitamente vinculado à noção de configuração social, é o de habitus ou "hábito social", que também funciona como ferramenta para se pensar a relação indivíduo-sociedade para além da dicotomia sujeito/objeto.

\begin{abstract}
Esse Habitus, a composição social dos indivíduos, como que constitui o solo comum de onde brotam as características pessoais mediante as quais um indivíduo difere dos outros membros da sociedade. Dessa maneira, alguma coisa brota da linguagem comum que o indivíduo compartilha com os outros e que é, certamente, um componente do habitus social - um estilo mais ou menos individual, algo que poderia ser chamado de grafia individual inconfundível, que brota da escrita social. [...] (ELIAS, 1994, p. 150).
\end{abstract}

O indivíduo, pertencente por nascimento a uma ordem social, carrega em si o habitus de um grupo, ao mesmo tempo em que, em maior ou menor grau, esse habitus é individualizado por ele de uma maneira específica. Elias descreve o habitus das sociedades complexas como distribuído em camadas referentes aos diferentes planos interligados dessa sociedade. Dentre essas camadas, para cada indivíduo, uma assumirá especial proeminência, geralmente a camada de filiação a um determinado grupo social de sobrevivência, como, por exemplo, uma tribo ou uma nação (ELIAS, 1994, p. 151).

Lançando mão dos conceitos eliasianos, propomos que no caso de Alô Guimarães, por mais singular que fosse sua posição na configuração social de Curitiba, traz em si o habitus social dessa comunidade.

[...] ele está inserido num complexo funcional de estrutura
bem definida, deve conformar-se a ele, moldar-se de acordo
com ele e, talvez, desenvolver-se mais, com base nele. Até a
sua liberdade de escolha entre as funções preexistentes é
bastante limitada. Depende largamente do ponto em que ele
nasce e cresce na teia humana, das funções e relações de
seus pais e, em consonância com isso, da escolarização que
recebe (ELIAS, 1994, p. 21).

Alô Guimarães não foi o primeiro médico a atuar em Psiquiatria no Paraná. Desde o começo do século XX, a partir da inauguração do Hospital Psiquiátrico Nossa Senhora da Luz, em 1903, existiu em 
Curitiba uma atenção médica à loucura. Em seu momento inaugural, no entanto, esta se caracterizou não como uma especialidade clínica, propriamente dita, mas como uma prática asilar ou hospitalar a cargo do clínico geral (OYUAMA, 2006).

O ensino na Psiquiatria, previsto para ser uma cadeira do último ano do curso de Medicina, esteve presente no currículo da Universidade do Paraná desde a fundação do curso em 1913 (ALVES, 2007). Teve início em 1918 com a primeira turma de sextanistas e consistia de um estágio, ou de uma série de momentos de observação dos internos do Hospital Psiquiátrico Nossa Senhora da Luz, orientados pelas explanações do professor regente da cadeira de Clínica Psiquiátrica, sendo os alunos aprovados por freqüência.

No decorrer das primeiras três décadas do século $X X$, o cenário gradualmente se modifica. Em meados dos anos 30, as novas técnicas terapêuticas, que eram experimentadas em São Paulo e no Rio de Janeiro, passam a ser incorporadas às práticas do hospício curitibano; são defendidas teses de doutoramento com assuntos da Clínica Psiquiátrica; surgem algumas primeiras publicações em periódicos locais sobre o tema; institui-se a Cátedra de Psiquiatria na Universidade do Paraná. O Dr. Alô Guimarães está intimamente envolvido em todos estes processos.

Alô Guimarães nasceu em Curitiba, em 1903, numa família tradicional. Por parte de pai, General Theodorico Gonçalves Guimarães, é um nacariano. ${ }^{1}$ Ainda que carregasse o emblema de uma ascendência aristocrática, era o quinto de nove filhos, de uma família sem muitos recursos financeiros.

Acadêmico dedicado, concluiu o curso de Medicina como melhor aluno da turma de 1927, tendo sido escolhido orador. Somando-se aos esforços e méritos pessoais, suas relações sociais e familiares certamente alavancaram sua carreira.

Durante os anos de Faculdade, face à necessidade de custear o dispendioso curso de Medicina, é o irmão, Acir Guimarães, redator chefe da Gazeta do Povo, que Ihe arruma um emprego como jornalista. As matérias à época não eram assinadas, o que dificulta rastrear os assuntos sobre os quais Alô escreveu.

Todavia, em 1925, quando Alô está no terceiro ano da Faculdade há uma sessão no jornal, cujo título é "Consultório Médico!". Nela, o jornalista - que assina "Dr. Guimarães" - responde a consultas dos leitores. "Sr. Fulano, tome elixir composto. Sra. Beltrana, procure um médico imediatamente". Não são revelados nem os nomes completos dos leitores, nem os seus problemas.

Um personagem que muito influenciou a trajetória do Dr. Alô foi seu tio, o médico Petit Carneiro ${ }^{2}$. São vários os momentos em que, profissional renomado na cidade e Professor da Universidade do Paraná, auxilia o sobrinho. Além de servir-lhe como inspiração e de tutor em sua carreira acadêmica, foi responsável pela colocação de 
Alô no cargo de monitor de Histologia e, depois de formado, de médico atendente no Hospital Psiquiátrico Nossa Senhora da Luz. Outro relacionamento próximo e significativo foi com Manoel Ribas ${ }^{3}$, o Interventor do Estado do Paraná no governo Vargas, entre os anos de 1932 e 1945. O cargo de médico e homem de confiança do governador foi decisivo na valorização e na solidificação da posição de destaque alcançada por Alô logo após a sua formatura, como médico do governo, responsável pelo Gabinete Médico Legal do Estado. Principalmente, foi um elemento decisivo para o início da sua bem sucedida carreira política. A influência pessoal de Manoel Ribas se fez presente, também, nos hábitos e nas atividades que Alô desenvolveu, em especial, no turfe e na criação de cavalos, esporte ao qual foi introduzido pelo interventor e que ocupou grande parte de suas horas vagas a partir da década de 50 .

É nessa rede de alianças e interdependências que se percebem as bases de muitas de suas oportunidades de engajamento institucional. Há uma linha, que passa pelo irmão Acir e que conecta Alô Guimarães às atividades jornalísticas e literárias, que incluem sua participação nas discussões e formação do Estatuto dos Jornalistas em 1925, e desemboca, em 1930, na sua atuação como um dos fundadores e, posteriormente, colaborador assíduo da Revista Médica do Paraná. Outra linha estabelece uma relação entre o tio - Petit Carneiro - , a academia, o Hospital Psiquiátrico Nossa Senhora da Luz, a especialidade Psiquiátrica e a docência; ainda outra, que o conecta através da sua proximidade com o governador do estado, à vida pública e à atuação em seus inúmeros cargos políticos: secretário da saúde, prefeito, deputado, senador.

A forma como esses vínculos são estabelecidos, dentro da rede cada vez mais complexa de atividades e relações que se desenvolviam na cidade, configura a posição destacada deste psiquiatra, e influencia, também, como conseqüência, a demarcação do campo da Psiquiatria na sociedade curitibana. O alcance da influência que o especialista atinge não se pauta na originalidade de seu pensamento ou de suas práticas, mas na sua inscrição numa racionalidade que já estava dada: um jogo de interdependência social onde as elites locais buscavam ocupar lugares que ofereciam chances de prestígio e poder.

Mas como compreender o valor e significado da contribuição individual de Alô Guimarães? Dr. Alô é detentor de uma produção autoral que se destaca no universo das poucas publicações da Curitiba da primeira metade do século XX. A análise de seus escritos revela que, a diferentes públicos, eram dirigidos discursos diversos, ainda que não necessariamente excludentes. E são muitas e variadas as esferas de sua atuação: conselhos médicos no jornal diário; textos médicos sobre Psiquiatria, mas também, sobre Hepatologia, 
Cardiologia, Medicina Legal; Aulas Magnas; discursos de paraninfo, e discursos políticos.

Em relação à sua visão da Psiquiatria, foram identificados três textos de interesse, publicados na Revista Médica Paranaense, que serão aqui analisados. O primeiro, a Aula Inaugural dos cursos da Faculdade de Medicina, do ano de 1938, intitulada "A ciência psiquiátrica, seu mérito, sua evolução e suas conquistas no terreno da clínica terapêutica" (GUIMARÃES, 1938). Os outros dois são discursos de Paraninfo, proferidos às turmas de Medicina formadas pela Universidade do Paraná em 1947 e 1949, intitulados, respectivamente, $O$ significado humano da carreira médica (GUIMARÃES, 1947), e O valor da cultura na formação espiritual dos médicos (GUIMARÃES, 1949).

$\mathrm{Na}$ avaliação destes textos, percebe-se que o seu sucesso não decorre da relevância da sua contribuição científica, nem se observa uma preocupação com coerência epistemológica. Por exemplo, na conferência de 1938, o professor de Clínica Psiquiátrica dirige-se a todo o corpo discente, em defesa de uma Psiquiatria que, a despeito de que fosse "falível a sua autoridade científica e pouco convincentes os índices de sua argumentação", anunciava progressos surpreendentes no campo da compreensão e tratamento das doenças mentais. Liberta do "mundo imaginário da metafísica", a Psiquiatria apresentada por Alô era animada pelo "espírito científico", e sedimentava-se nas "vitórias puramente objetivas da terapêutica clínica", tendo por objetivo "resolver os problemas da fisiologia e evidenciar as leis da bioquímica" (GUIMARÃES, 1938, p. 105-108). Após um apanhado do histórico da disciplina, Alô anuncia os desenvolvimentos que informam sua prática: os exames laboratoriais, as possibilidades diagnósticas da escola constitucionalista caracteriológica de Kretschmer ${ }^{4}$ e os modernos métodos de tratamento biológico: a Malarioterapia e a Insulinoterapia ${ }^{5}$. Uma fala que afirmava a cientificidade de um começo "positivo" de ano acadêmico (GUIMARÃES, 1938).

Em outra oportunidade, no ano de 1949, proferiu um discurso de paraninfo onde as tintas eram outras. O texto, intitulado "O valor da Cultura na formação espiritual dos médicos", nas palavras do autor "entoava um cântico de aclamação festiva ao pensamento". Utilizando-se de um palavreado elaborado e solene, Alô citava o dramaturgo e ensaísta místico Maeterlink, que havia ganhado o Premio Nobel de Literatura em 1911: "Não esqueçamos que nada nos acontece que não seja da mesma natureza que nós mesmos". Ainda que o cientificismo continue presente, é notável o quanto este se traveste de maneira a atender à expectativa da platéia. É nessa característica formal, de adequação ao habitus, mais que no próprio conteúdo da fala, que pode ser encontrada uma justificativa para o destaque de Alô em tantos e tão diversificados meios. 
Nas palavras de Elias,

[...] há situações que, para serem controladas, requerem não homens dotados daquilo que chamamos, de modo romântico de "originalidade" ou "força criativa", não personagens agressivos e dinâmicos, mas homens cuja marca caracterítica é uma calma e regular mediocridade. (ELIAS, 2001, p. 141)

A compreensão do lugar de poder que se constela com Alô Guimarães demanda a observação do contexto sócio-cultural da Curitiba nessa primeira metade do século passado. O que estava acontecendo em Curitiba nesse período? Observa-se que, assim como em outros centros urbanos, a primeira metade do século XX foi marcada por mudanças demográficas e urbanísticas significativas.

Sede da capital do Paraná, desde que havia sido emancipada da província de São Paulo, em 1853, na virada do século, Curitiba vivia uma ambivalência (OLIVEIRA, 2002). Por um lado, estava a pretensão de ser cidade grande e moderna. Uma ambição que era sustentada pela própria condição de capital da província que previa uma infra-estrutura de metrópole, epicentro econômico, político e cultural. Muitos esforços foram feitos neste sentido: iniciativas públicas de melhorias nos aparelhos urbanísticos e no atendimento à educação e à saúde pública.

Porém, os avanços em direção a uma desejada modernidade vêm colados ao aumento populacional, o que trouxe o agravamento de problemas como mendicância, criminalidade, falta de saneamento, transporte, etc. E, ainda que a pobreza tenha atingido novos índices, não era novidade.

Curitiba sempre foi pobre. No século XVIII, "a Câmara Municipal informava que a maior parte da população de Curitiba, por falta de condições econômicas, comia sem sal" (WACHOWICZ, 2006, p. 27). No século XIX, um primeiro, mas acanhado ciclo de desenvolvimento é alavancado pela exportação da erva-mate para a Argentina e o Uruguai, depois que o ditador do Paraguai, Francia, por motivos políticos, proibiu a venda dos produtos paraguaios para estes países. No início do século $X X$, o mate representava praticamente um terço do orçamento do estado (WACHOWICZ, 1972, p. 134). É sob essa base econômica, somada ao aumento da extração e comércio da madeira, que se dá durante a primeira grande guerra, que se observa - gradual desenvolvimento da indústria, dos serviços e de um comércio exterior. No entanto, se o Brasil, enquanto produtor de bens primários para a exportação, estava na periferia do mundo ocidental, - Paraná, produtor da "exótica" erva mate e, mais tarde, de café, ambos "bens de sobremesa", estava na periferia da periferia (OLIVEI RA, 2002). 
E daí a ambivalência: uma capital que se esforça e falta, e um centro urbano que permanece, econômica, política e culturalmente, periférico.

Esse dilema pode ser percebido, também no processo de organização do ensino superior em Curitiba. A preocupação com a formação de uma elite intelectual e o projeto de uma Universidade estão presentes na sociedade paranaense desde o início do período republicano. A primeira proposta de fundação de uma universidade no Paraná, elaborada por Rocha Pombo, data de 1892 (CAMPOS, 2008; WACHOWICZ, 2006).

A história da fundação da Universidade do Paraná, em 1912, e da sua sobrevivência durante a primeira metade do século XX é marcada pela participação de diferentes grupos de profissionais locais num esforço convergente ao estabelecimento de uma instituição que deveria colaborar para que o Paraná pleiteasse uma posição de destaque entre os estados brasileiros mais prósperos. Tanto para os envolvidos no projeto, quanto para grande parte da intelectualidade, significava um símbolo indelével da emancipação intelectual do estado (WACHOWICZ, 2006, p. 59). É, todavia, uma emancipação precária e que se sustenta a duríssimas penas.

As atividades acadêmicas, nesse primeiro momento, eram mantidas por um corpo docente que, ainda que esforçado e idealista, compunha-se de professores improvisados, sem garantia de vencimentos, sobrecarregados por duas, três cátedras, além das aulas básicas, e ameaçadas tanto pelas incertezas e a crise econômica deflagrada pela grande guerra quanto pelas políticas centralizadoras do governo federal.

Com a reforma que extinguiu o ensino livre e estabeleceu a inspeção federal para o reconhecimento das instituições de ensino superior no Brasil, conhecida como a Lei Maximiliano (decreto 11.530, de 18/03/1915), a Universidade do Paraná correu sérios riscos de ser fechada, como aconteceu, na ocasião, com as Universidades de São Paulo e de Manaus. Mas, ainda que a sua restauração plena só viesse a ocorrer em 1946, a Universidade do Paraná, emblema do progresso moral e material do estado, não desapareceu. Como resultado do esforço conjunto de governo, professores, autoridades e alunos conseguiu-se revogar a exigência, estipulada pela nova lei, de um mínimo de 100 mil habitantes para ser cidade sede de ensino superior e estabelecer o reconhecimento das Faculdades isoladamente (Direito, Engenharia e Medicina), as quais passaram, embora com autonomia didática, a atuar sob direção administrativa única (WACHOWICZ, 2006; BURANOW; SIQUEIRA, 2007).

A consolidação da Psiquiatria, não só como um campo de prática clínica, mas, principalmente, como saber científico propriamente instituído, se dá, nesse contexto, como um dos quesitos a serem atendidos no rol que uma agenda de cidade moderna impunha. Esse 
era um dos elementos, no desenvolvimento mais amplo das unidades sociais, que deveriam ser introduzidos, a exemplo dos maiores centros urbanos do país, para sustentar o ideal social de "metrópole moderna".

A instituição da cátedra de Clínica Psiquiátrica da Universidade do Paraná, juntamente com o concurso para professor catedrático, em 1936, é um episódio que, ao mesmo tempo em que pode ser compreendido como o momento chave da consolidação da Psiquiatria no estado, ilustra como as mudanças na estrutura da vida conjunta em Curitiba engendravam um espaço de poder que coube a Alô Guimarães ocupar.

Desde 1933, o Regimento Interno da Faculdade de Medicina no Paraná, atendendo à regulação legislativa do ensino superior no Brasil, promulgada pelo Estatuto das Universidades Brasileiras, de 11 de abril de 1931, previa o recrutamento do corpo docente através de concurso de títulos e de provas. Desde então - ainda que o quadro de professores já estivesse completo, anteriormente à aprovação do novo Regimento, e os catedráticos que já atuavam na Universidade tivessem sido reconduzidos ao cargo, através de concurso só de títulos - os concursos para professor passaram a fazer parte do universo de "eventos culturais" da cidade.

No relatório sobre as atividades do ano de 1936, o Reitor da Faculdade de Medicina, Dr. Vitor Ferreira do Amaral e Silva, ao se reportar aos diversos concursos que haviam sido realizados e aos novos professores que haviam sido acrescidos ao corpo docente, destaca as circunstâncias do concurso pra a cátedra de Clinica Psiquiátrica.

\begin{abstract}
Embora tivéssemos feito muitos convites para as comissões examinadoras de professores de outras Faculdades, só tivemos a ventura de conseguir, para o Concurso de Clínica Psiquiátrica, a presença dos laureados mestres Prof. Antonio Austregesilo, da Faculdade de Medicina do Rio de Janeiro, Prof. Pacheco e Silva, da Faculdade de Medicina da Universidade de São Paulo, e Prof. Heitor Carrilho, da Faculdade Fluminense de Medicina (FACULDADE DE MEDICINA DO PARANÁ, 1937, p. 2).
\end{abstract}

Ainda que as dificuldades em compor as bancas de concursos já sejam motivo de nota do Reitor no relatório do ano anterior (FACULDADE DE MEDICINA DO PARANÁ, 1936, p. 4), nenhum documento explicita razões pelas quais outros professores declinaram os convites da Universidade do Paraná. No entanto, o dado, por si só, lança alguma perspectiva sobre o prestígio que a instituição paranaense gozava no meio. 
O vulto das solenidades referentes ao concurso de 1936, que aprova Alô Guimarães para a recém instaurada cátedra de Clínica Psiquiátrica, bem como a repercussão que estas tiveram na imprensa local, foram sem precedentes. As diversas etapas das provas, conferências e homenagens povoaram as páginas dos dois principais jornais diários de Curitiba e renderam várias matérias na Revista Médica do Paraná.

Com detalhes, os curitibanos foram informados da chegada e recepção dos professores da banca examinadora na cidade; dos horários, local e condições em que se realizariam as provas escrita, prática e didática; sobre o sorteio do ponto; da sessão solene onde o Reitor e a Congregação da Faculdade de Medicina saudaram os visitantes; da sessão extraordinária da Associação Médica do Paraná em homenagem aos mesmos, que reuniu associados, professores e acadêmicos da Faculdade de Medicina e inúmeras autoridades locais no salão nobre do tradicional Club Curytibano, para ouvir as conferências proferidas pelos psiquiatras visitantes; e, sobremodo, do resultado do concurso:

\begin{abstract}
Ainda ontem, o resultado final de um brilhante concurso realizado para o preenchimento da cadeira de Psiquiatria da Faculdade de Medicina do Paraná, foi anunciado com a vitória do Dr. Alô Guimarães, distinto médico patrício, moço dos mais ilustres da atual geração, profissional de méritos e cidadão credenciado sobremodo na sociedade paranaense. (Gazeta do Povo, 11.11.1936, p. 1)
\end{abstract}

Percebe-se, no texto acima, que não foi sem importância o fato de que o prestigioso cargo havia sido ocupado por um "patrício", um personagem credenciado da sociedade paranaense. Num contexto onde as variáveis sociais se encontravam em rápida transformação, a escolha de um indivíduo cujo status e inclusão social relacionavam-se à vida e às tradições comunitárias representava uma afirmação da identidade e da coesão grupal no contexto paranaense.

O ano de 1936, no Paraná, se configura como um marco importante na instituição e consolidação da Psiquiatria como um lugar social, que promove discursos e práticas modernas sobre o fenômeno da doença mental. Observar a forma como a sociedade de Curitiba se organizou nesse período e como o poder se distribuiu nessa configuração, permite perceber características distintivas da constituição local de um saber psiquiátrico provinciano, em suas dimensões epistemológicas, práticas e técnicas.

Retomando a discussão de Elias da relação indivíduo-sociedade, pode-se evidenciar aspectos característicos da forma de ser em sociedade, ou seja, do habitus local, que estão presentes na trajetória do Dr. Alô e seu imbricamento no processo histórico de desenvolvimento de Curitiba. 
O mesmo impasse se estabelece nos dois âmbitos, simultaneamente. Como fazer jus a um status recebido (e não conquistado) de capital ou de membro de uma elite? À expectativa de "glorificação do destino" tanto da cidade quanto dos seus heróis nacarianos, justapõe-se uma escassez dos meios econômicos e culturais para sustentar essa expectativa.

Através da inscrição na "boa sociedade curitibana", encontramos as articulações entre Alô Guimarães e suas múltiplas atividades, inclusive sua dedicação ao Hospital Espírita. Os dirigentes da Federação Espírita do Paraná eram, também, pertencentes a essa "rede" de pessoas não só companheiros na localidade, mas que se conhecem há gerações. É o código comum e os vínculos afetivos específicos, que permeiam o círculo das "famílias antigas", que permitem compreender como se estabelece a relação entre Psiquiatria e Espiritismo, nesse caso.

Por nascimento, membro da elite sócio cultural local, o que já lhe conferia, de largada, um grande trunfo social, Alô Guimarães soube, como poucos, moldar seu comportamento ao habitus local para, em acordo com os padrões e compromissos do seu quadro social, diferenciar-se e destacar-se dos demais.

Na configuração da Psiquiatria paranaense, Alô Guimarães teve uma função de "representante nomeado" e reprodutor do saber científico. Vislumbra-se um cenário onde a constituição da Psiquiatria, como especialidade médica, se dá de forma tardia e encarnada na figura do "Professor Especialista", responsável pela transmissão das últimas descobertas científicas na área.

O prestígio individual do Dr. Alô Guimarães, que transcende o campo da medicina e se inter-relaciona com questões políticas, sociais e culturais, repercute nas práticas de atendimento aos doentes mentais. Com sua ascensão à cátedra, observa-se, em Curitiba, finalmente, a Psiquiatria, entendida como um saber científico, assumir um papel central no diagnóstico e tratamento da loucura.

\section{Referências Bibliográficas}

ALVES, E. S. A psiquiatria na Faculdade de Medicina do Paraná. In: COSTA, I. A.; LIMA, E. C. (Orgs.)., O ensino da Medicina na Universidade Federal do Paraná (p. 256- 261). Curitiba: Editora UFPR, 2007.

ALVES, E. S; PILLOTO, M. Alô Ticoulat Guimarães: uma vida ilustre dedicada à Medicina e ao ensino da Psiquiatria. Curitiba: Fundação Santos Lima, 1994. 341p.

BODANZKY, L. Bicho de Sete Cabeças [Filme]. Direção de Laís Bodansky. Brasil. 2000. 74 minutos.

BRASIL. Decreto n. 19.851 de 11 de abril de 1931. Estatuto da Universidade Brasileira. 
BURANOW, U. G; SIQUEIRA, M. D. Universidade Federal do Paraná: história e estórias: 1912-2007. Curitiba: Editora da UFPR, 2007.

BUENO, A. C. O canto dos malditos. Rio de Janeiro: Rocco, 2000. CAMPOS, N. Intelectuais paranaenses e as concepções de universidade (1912-1950). Curitiba: Editora da UFPR, 2008.

Carneiro, D.; Vargas, T. História Biográfica da República no Paraná. Curitiba: Banestado, 1994.

CARNEI RO, M. Petit Carneiro: quarenta anos de atividades médicas. Curitiba, Papelaria Requião, 1953.

FACULDADE DE MEDICINA DO PARANÁ. Regimento Interno. Curitiba: Max Roesnner \& Filhos, 1933.

FACULDADE DE MEDICINA DO PARANÁ. Relatório do ano de 1935. Curitiba: Tip. João Haupt e Cia, 1936.

FACULDADE DE MEDICINA DO PARANÁ. Relatório do ano de 1936. Curitiba: Tip. João Haupt e Cia, 1937.

GAZETA DO POVO. Mais um ilustre catedrático para a Faculdade de Medicina do Paraná, Curitiba, 11 de novembro, 1936. p. 1.

GUIMARÃES, A. T. Contribuição Paranaense ao estudo da punç̧ão sub-occipital. Revista Médica do Paraná, Curitiba, v. 5, n. 4, p. 87-93, 1936.

GUIMARÃES, A. T. A ciência psiquiátrica: seu mérito, sua evolução e suas conquistas no terreno da clínica e da terapêutica. Revista Médica do Paraná. Curitiba, v. 7, n. 3, p. 105-132, 1938.

. O significado humano da carreira médica. Revista Médica do Paraná. Curitiba, v. 16, n. 3, p. 65-71, 1947.

O valor da cultura na formação espiritual dos médicos.

Revista Médica do Paraná. Curitiba, v. 18, n. 6, p. 423-429, 1949.

ELIAS, N. A sociedade dos Individuos. Tradução de Vera Ribeiro. Rio de Janeiro: Jorge Zahar, 1994.

A sociedade de Corte. Tradução de Pedro Sussekind. Rio de Janeiro: Jorge Zahar, 2001.

Introdução à Sociologia. Tradução de Maria Luiza Ribeiro Ferreira. Lisboa: Edições 70, 2008.

LIMA, A. A.; HOLANDA, A. F. História da Psiquiatria no Brasil: uma revisão da produção historiográfica (2004-2009). Estudos e Pesquisas em Psicologia, Rio de Janeiro, v. 10, n. 2, p. 572-595, 2010. Disponível em: <http://www.revispsi.uerj.br/v10n2/artigos/pdf/v10n2a17.pdf>. Acesso em: 29 nov. 2010.

OLIVEIRA, D. Curitiba e o mito da cidade modelo. Curitiba: Editora UFPR, 2002.

OUYAMA, M. Uma máquina de curar: o Hospício Nossa Senhora da Luz em Curitiba e a formação da tecnologia asilar (final do século XIX e início do século XX). Tese (Doutorado em História) - Setor de 
Ciências Humanas, Letras e Artes, Universidade Federal do Paraná, Curitiba, 2006.

PEREIRA, L. M. F. Reformas da Ilusão: a terapêutica psiquiátrica em São Paulo na primeira metade do século XX. Tese (Doutorado em Saúde Mental) - Faculdade de Ciências Médicas, Universidade Estadual de Campinas, Campinas, 1995.

Mestres da Psiquiatria brasileira em Curitiba. Revista Médica do Paraná. Curitiba, v. 5, n. 11, p. 441, 1936.

WACHOWICZ, R. História do Paraná. Curitiba: Ed.Gráfica Vicentina, 1972.

. Universidade do Mate. Curitiba: Editora UFPR, 2006.

\title{
Endereço para correspondência
}

Andrea de Alvarenga Lima

Av. Cândido de Abreu, 660, conj. 708, CEP 80530-000, Curitiba-Paraná, Brasil

Endereço eletrônico: alvarenga.lima@gmail.com

Adriano Furtado Holanda

Praça Santos Andrade, 50, Sala 215, Ala Alfredo Buffren, CEP 80060-240, CuritibaPR, Brasil

Endereço eletrônico: aholanda@yahoo.com

Recebido em: 07/12/2010

Aceito para publicação em: 07/02/2011

Acompanhamento do processo editorial: Ana Maria Jacó-Vilela

\begin{abstract}
Notas
* Mestranda em Psicologia.

** Doutor em Psicologia.

${ }^{1}$ Como ficaram conhecidos os descendentes do Comendador Manoel Antônio Guimarães [1813 - 1893], depois Barão e Visconde de Nácar. Figura eminente do empresariado e da política paranaense nos tempos do Império, o Visconde de Nácar foi grande defensor da monarquia, líder do Partido Conservador entre 1850 e 1889, e ocupou vários cargos de destaque, tanto no legislativo quanto na Guarda Nacional.

${ }^{2}$ Abdon Petit Guimarães Carneiro [1876-1940], neto do Visconde de Nácar, formou-se em medicina em 1898, na Faculdade de Medicina do Rio de Janeiro. Além de destacada atuação em várias epidemias (varíola, Paranaguá/PR, 1898; peste bubônica, Campos/RJ, 1901; tifo, Curitiba/PR, 1917; gripe espanhola, Curitiba/PR, 1918), dirigiu, por muito tempo, o serviço médico da Caixa de Aposentadorias e Pensões dos Ferroviários da R.V.P.S.C. e atuou como clínico no Hospital Psiquiátrico Nossa Senhora da Luz. Foi um dos fundadores e docentes mais ativos dos primeiros anos da Universidade do Paraná, dedicando-se, de forma especial, à cadeira de Histologia e Embriologia Geral (Carneiro, 1953).

${ }^{3}$ Manoel Ribas [1873 -1946], natural de Ponta Grossa, Paraná, permaneceu, indicado por Getúlio Vargas, durante treze anos à frente do governo paranaense, ora como interventor (1932 a 1934), ora como governador (1935 a 1937), e outra vez como interventor (1937 a 1945) (Carneiro \& Vargas, 1994).

${ }^{4}$ Ernst Kretschmer [ 1888 - 1964]; Psiquiatra alemão conhecido por ter desenvolvido um sistema de classificação baseado em três tipos principais de aspectos corporais (astênico ou leptossômico - magro, pequeno, fraco; atlético - musculoso, ossos grandes; e, pícnico - gordo, atarracado). Cada um destes tipos estaria associado a certas características de personalidade, e, em formas extremas, de psicopatologia.
\end{abstract}


${ }^{5} \mathrm{~A}$ racionalidade dos chamados tratamentos biológicos consistia em, através de uma alteração brusca de alguma propriedade do corpo ou do espírito, produzir um choque que causasse uma dissociação no paciente. Na Malarioterapia, a inoculação do vírus da malária provocava acessos febris delirantes; na Insulinoterapia, injeções diárias de doses crescentes de insulina têm por objetivo a instalação de comas hipoglicêmicos (Pereira, 1995). 